\title{
Political Arithmetic: Simon Kuqnets and the Empirical Tradition in Economics
}

\author{
by Robert William Fogel, Enid M. Fogel, Mark Guglielmo, and Nathaniel Grotte \\ Chicago: University of Chicago Press 2013 \\ ISBN: 9780226256610 \\ Paperback, \$32.00, 168 pp.
}

\author{
Reviewed by Rick Szostak \\ Department of Economics, University of Alberta
}

Simon Kuznets is a worthy subject for a biography. Winner of the third Nobel Prize in Economics, he is most well-known for his pioneering role in the development of national income accounts. Yet, in thirty books and two hundred articles he made critical contributions to a variety of other fields, including the relationship between population trends and economic growth. He was, in turn, the president of both the American Statistical Association and American Economic Association.

This is an academic biography, intended to highlight Kuznets' role in the intellectual developments of his time. Its first author, Robert Fogel, was a Kuznets student and later a Nobel Prize winner himself.

The introduction summarizes some of the major advances in economic well-being over the most recent centuries, with an emphasis on the advances in health and nutrition that were the main focus of Fogel's research for decades. Kuznets appears rarely, though it is noted that he appreciated that the national income accounts which he helped to develop seriously underestimated rates of advance in areas like healthcare and education.

The first numbered chapter summarizes the development of economics before the First World War (Kuznets would earn his BA in 1923 and $\mathrm{PhD}$ in 1926). It is argued that economists gained a role in public policy from the 1880s due to three factors: increased concern about the power of big business over both labour and small business, the increased numbers of academic economists, and (less approvingly, it seems) increased interest in developing a 'welfare state' that would correct income inequalities generated by the market. Important developments included the Bureau of Labor Statistics and a variety of government commissions: these collected statistics of various sorts, employed numerous economists, and argued for a variety of government interventions.

Chapter 2 discusses at length how the First World War highlighted the need for better statistics to guide both public and private decisions. The National Bureau of Economic Research (NBER) was created in 1919, with private financing but a diverse board and a dedication to impartial reporting. Its first concern was to estimate national income and how this was divided across both social groups and industries. Kuznets would be associated with the NBER for most of his career.

Chapter 3 shows how the Great Depression and the advent of the Second World War both encouraged the development of national income statistics: to establish how severe the Depression was and how it was distributed, and to estimate the possibilities for war production. Kuznets was seconded from the NBER to the government, and supervised the first set of national income accounts that would inform public policy. Concepts such as GNP and GDP thereafter became a focus of public policy discussions. The authors tangentially also devote a little space to attempting to burnish Herbert Hoover's reputation and critique Roosevelt's actions. The chapter briefly celebrates the role of national income accounts during the war, and devotes far more space to reviewing the diverse roles played by other economists in the war effort. The chapter concludes, rather disjointedly, with 
a one-sided review of policy debates in the early postwar period. It is noted in passing that Kuznets had a more favourable view of population growth than did many others at the time.

Kuznets finally takes centre stage in chapter 4. In order to investigate the causes of economic growth, he wished to develop comparable national income statistics from twenty or so developed countries over the previous half century. When the NBER proved unsupportive of this project, he obtained funding through the Social Science Research Council, and ten monographs resulted. The data showed a slight positive effect of population growth on economic growth, an important impact of shifting labour out of agriculture, and a correlation at the time between growth and improvements in income distribution. In 1966 Kuznets published his most famous book, on the causes of economic growth. Building upon his careful analysis of data, it proffered not a simplistic monocausal view but a complex set of interactions, where key variables changed through the development process. He recognized that increases in productivity were far more important than increases in capital stock, and in turn reflected primarily technological innovation but also institutional change. Kuznets again argued for the positive impact of moderate rates of population growth, but urged policies to reduce much higher rates of population growth that thwarted efforts to raise incomes in poorer countries. Kuznets stressed that differential rates of innovation meant differential rates of growth across sectors. Economic growth is never a smooth and even process. Trade, foreign investment, and migration were generally viewed favourably. Though the effects of growth were predominantly benign, Kuznets noted negative impacts such as unemployment in sectors lacking innovation and the challenges of rapid urbanization.

Kuznets devoted much of his research to the relationship between population and economic growth. He generally stressed the positive impacts of the former on the latter: increased innovation, savings, economies of scale, and openness to novelty (because of a more youthful population). He in particular stressed the many benefits of decreased mortality, especially among the young, and the health advances this reflected. Even more centrally, he argued for the positive effect of increased population density on innovation: this would ensure that population growth could co-exist with economic growth long into the future, a possibility that many doubted at the time. But despite these general positive effects, Kuznets appreciated that unprecedented population growth in very poor countries likely slowed growth.

The authors note that - as Kuznets himself appreciated - some of the theoretical generalizations Kuznets derived from the data have since been questioned. But most are still subjects of investigation. The authors praise Kuznets' emphasis on deriving theory from careful observations of both the past and the present, and rue the exaggerated emphasis on solely mathematical modelling among later generations of economic theorists.

Chapter 5 explores the methods employed by Kuznets. Kuznets is lauded for being a realist about empirical analysis: he recognized that all data are imperfect, urged researchers to understand how data was generated, urged modesty in drawing theoretical conclusions or performing quantitative analysis, and most importantly urged sensitivity analysis to establish the robustness of findings. As a theorist Kuznets was careful to stipulate the empirical limitations on which his theoretical conjectures were based. Those who drew upon him were not always so careful: his suggestion that income inequality might tend to rise in early stages of economic development but would fall later came to be celebrated by many as the "Kuznets curve," and was viewed as something close to an iron law of economic development.

The brief chapter 6 surveys Kuznets' institutional legacies: a handful of research programs at the NBER and SSRC that continue, and of course the continued use of the national income accounts that he pioneered. Kuznets, it is noted, never shied from admitting the limitations of such accounts, and would have, it is felt, have applauded efforts to both improve and supplement these.

The even shorter chapter 7 is an odd fit, surveying diverse economic developments a quarter-century after Kuznets' death in 1985. Kuznets, we are told in passing, would have been unsurprised by continued technological innovation or by rapid economic growth in East Asia.

The book is an engaging read and filled with interesting detail. It also reflects Fogel's opinion on a variety of issues, not all clearly related to the theme of the book. Almost as many works by Fogel are cited as works by Kuznets. Readers of this journal may find chapters 4 and (to a lesser extent) 5, where Kuznets' research on the links between population and economic growth are engaged, of particular interest. 